\title{
Understanding the structure of the set of rational numbers: a conceptual change approach
}

\author{
Xenia Vamvakoussi*, Stella Vosniadou \\ Cognitive Science Laboratory, Department of Philosophy and History of Science, National and \\ Kapodistrian University of Athens, Panepistimiopolis 15771, Ilissia, Athens, Greece
}

\begin{abstract}
In the present article, we argue that the conceptual change approach to learning can apply in the case of mathematics, taking into consideration the particular nature of mathematical knowledge and the neurobiological bases of mathematical cognition. In the empirical study that is reported in this article, we investigated ninth graders' understanding of algebraic and structural properties of rational numbers, from a conceptual change perspective. We make the point that understanding rational numbers is not indiscriminately difficult. We show that prior knowledge about natural numbers supports students dealing with algebraic properties of rational numbers, while the idea of discreteness is a fundamental presupposition, which constrains students' understanding of density.
\end{abstract}

(C) 2004 Elsevier Ltd. All rights reserved.

Keywords: Conceptual change; Rational numbers; Density

\section{Introduction}

The conceptual change approach to learning has its roots both in the science education research tradition and the cognitive-developmental research tradition (Vosniadou, 1999). Both traditions took into consideration Kuhn's revolutionary account of scientific change (Kuhn, 1970). In the science education research tradition, researchers drew an analogy between the Piagetian ideas about accommodation and assimilation and the Kuhnian ideas about theory change in the history

\footnotetext{
${ }^{*}$ Corresponding author. Tel.: +30-210-7275506; fax: +30-210-7275504.

E-mail address: xenva@phs.uoa.gr (X. Vamvakoussi).
} 
of science. The key construct "scientific revolution" served as a source of hypotheses about how concepts change in the process of learning (Posner, Strike, Hewson, \& Gertzog, 1982). Within the cognitive-developmental research tradition, Piaget's thesis that cognitive development primarily involves changes in general logical capabilities was challenged and it was assumed that human cognition builds on a set of domain-specific systems of knowledge (Carey \& Spelke, 1996). Starting with Carey (1985), who extrapolated insights from Kuhn's ideas, developmental psychologists described cognitive development in terms of the reorganization of initial, domain-specific knowledge structures.

A considerable number of empirical studies have been conducted within the conceptual change theoretical framework in the case of science learning (Mason, 2001; Vosniadou, 1994a). But the conceptual change approach is not itself "domainspecific": it has been used to describe and explain aspects of learning in domains other than science, such as history (Limon, 2002). In the present study, we investigate students' understanding of certain properties of rational and real numbers. We will adopt the conceptual change theoretical framework developed by Vosniadou (1994b, 2002). But before presenting the design and results of that study, we will first argue that the conceptual change approach is relevant to mathematics learning.

\subsection{Are there scientific-like revolutions in mathematics?}

As we have already mentioned, in science education research, patterns of change in science history were related to patterns of change in science learning. However, in the case of mathematics there could be an argument that the particular nature of mathematical knowledge and its development is such that learning mathematics does not require radical change of concepts, but it is rather a matter of enriching prior knowledge.

Mathematics has traditionally been regarded as an exceptional domain of human knowledge, with particular characteristics, which differentiate it from any other discipline, even from its nearest neighbors, the natural sciences. Among others, there is one claim about mathematics that is particularly relevant to our discussion, namely the claim that mathematics is cumulative (Crowe, 1992; Kitcher, 1992). This view of mathematics is partly grounded on the belief that once a mathematical statement is proven, it can be safely and permanently added to the body of knowledge of mathematics. But mathematics can also be considered cumulative in the sense that a mathematical theory, once established, is never deposed by a latter theory (Crowe, 1975). In fact, this has been the main argument against the possibility of science-like revolutions in mathematics. The coexistence of Euclidean and non-Euclidean geometries is usually presented as an example: non-Euclidean geometries are a major breakthrough in the history of mathematics, yet Euclidean geometry is still valid after the change and there is no phenomenon of incommensurability about it.

It appears that Kuhn himself explicitly exempted mathematics from his analysis, as he was persuaded that there are no revolutions in mathematics, at least not in the same sense as in natural sciences. Although according to some analyses, 
mathematics and science bare more resemblances than traditionally believed (Kitcher, 1992), let us assume for the purpose of our discussion, that changes in mathematics are indeed not analyzable in the terms used for the natural sciences. And let us also accept that deciding whether a change in mathematics is "revolutionary" or not is a matter of definition (Corry, 1993; Crowe, 1992). The question whether revolutions, in the Kuhnian sense, occur in mathematics is still important to the extent that it provoked a fruitful discussion, which accelerated a change in the way the history of mathematics is viewed. New perspectives on the history of mathematics have questioned the claim that "the structure of mathematics accurately reflects its history" (Crowe, 1992) and have revealed that mathematical concepts undergo changes that cannot be described in terms of accumulation. For example, in the case of the concept of number, the shift from the Pythagorean concept of number, through the theory of proportions of Eudoxus to the concept of rational and Dedekinds' real numbers entails more than just expanding the initial concept. It entails changes in the meaning of the term "number". For example, the conceptualization of ratios of integers as numbers, rather than operations, can be accounted for as an ontological shift of ratios from the category of processes to the category of mathematical objects (Sfard, 1991). The shift from the irrational magnitudes to irrational numbers can also serve as an example (Dauben, 1984).

To summarize, we argued that for the purpose of deciding whether the conceptual change approach can apply to mathematics learning, one does not need to give an account for the change of mathematical theories, but for the development of mathematical concepts. From this perspective, it suffices to argue that there is more to the development of mathematical concepts than mere addition.

\subsection{Is there a domain-specific knowledge system pertaining to mathematical cognition?}

A basic assumption of the domain-specific approach to cognitive development is that human cognition builds on a set of domain-specific systems of knowledge, which are probably neurobiologically based and have developed through evolution (Carey \& Spelke, 1996).

There is increasing evidence from research with animals, human infants and individuals from different cultures (Butterworth, 1999; Dehaene, 1998; Gelman, 2000; Lipton \& Spelke, 2003) that the domain of number is sustained by a specific, innately determined system. The discrete nature of numbers has been proposed as one of the core principles of this system (Carey \& Spelke, 1994; Galistel \& Gelman, 1992).

The implications of this assumption are that some aspects of learning pertaining to the number concept are privileged, and thus easy to achieve, whereas others are not (Gelman, 2000; Stern, 2003). The first are compatible with the initial number concept, whereas the latter require reorganization of the existing knowledge structures, as predicted by the conceptual change approach. There is a considerable amount of empirical evidence to support this assumption: early understandings of 
natural numbers and their properties are privileged and support children's understanding of notions such as potential infinity (Hartnett \& Gelman, 1998). On the contrary, learning about rational numbers, their representations and their properties is considerably difficult and is bugged with numerous misconceptions (Carpenter, Fennema, \& Romberg, 1993; Gelman, 2000).

\subsection{What is the role of prior knowledge in mathematics learning? The case of the number concept}

In mathematics education research, there has been much evidence to show that prior knowledge about natural numbers stands in the way of understanding rational numbers. Students make use of their knowledge of whole numbers, to interpret new information about rational numbers (Moskal \& Magone, 2000; Resnick, Nesher, Leonard, Magone, Omanson, \& Peled, 1989). This gives rise to numerous misconceptions, pertaining both to conceptual and operational aspects of numbers. For example, properties of natural numbers such as "the more digits a number has the bigger it is" are used in the case of decimals. Misconceptions about fractions are connected to principles that apply only in the case of natural numbers (Stafylidou \& Vosniadou, this issue). In the context of mathematical operations, there are well known misconceptions, such as that "multiplication always makes bigger", which reflects the effect of prior knowledge about multiplication with natural numbers (Fischbein, Deri, Nello, \& Marino, 1985). Such results are compatible with the conceptual change theoretical framework, which predict difficulties in learning when the new knowledge to be acquired comes in conflict with what is already known (Vosniadou, 1994a).

\section{The present study}

The main purpose of the present study is to investigate the development of students' ideas about the structure of the set of rational numbers. The set of rational numbers is characterized by a property, namely density, which is radically different than that of the set of natural numbers, namely discreteness. More specifically, between any two different rational numbers there are infinitely many rational numbers, whereas between two successive natural numbers there is no other natural number. To develop the concept of density, one needs to realize that the concept of rational number unifies the concepts of decimal, fractional and whole numbers. This requires understanding the different representations of rational numbers and the way they are related to each other, as well as the interrelations between the various subsets of the set of rational numbers. This kind of understanding is difficult to achieve (Carpenter et al., 1993; Gelman, 2000; Moskal \& Magone, 2000). Moreover, the concept of density is closely related to the concept of infinity. The concept of infinity has various aspects, among which actual infinity is the most difficult to grasp (Fischbein, 1987; Lakoff \& Nunez, 2000; Tall, 2001; Tirosh, 1991). As already mentioned, early understandings of the principles underlying the structure of natural numbers support understanding of certain aspects of potential infin- 
ity. Children can infer that there are infinitely many natural numbers, based on the fact that for any natural number, there is always a next one. In some cases, the same thinking may support dealing with the concept of density. For example, prompting a student to find the arithmetic mean $m_{0}$ of two rational numbers $a, b$ and repeat the procedure for $a, m_{0}$ and so on, may lead the student to infer that there are infinitely many numbers between $a$ and $b$. This is a way of approaching the notion of actual infinity in a potential manner. It is our assumption, investigated by an ongoing study, that this kind of response does not necessarily imply that the student has achieved understanding of density. In a context that relates density to actual infinity, the concept of density is quite difficult to deal with. Moreover, as we have already argued, the idea of discreteness of numbers is deeply rooted, both in the initial knowledge system pertaining to mathematical cognition and in later conceptual structures pertaining to the number concept. Empirical research on the concept of rational and real numbers and the concept of infinity (Hannula, Maijala, Pehkonen \& Soro, 2001; Malara, 2001; Merenluoto \& Lehtinen, 2002, this issue) shows that misconceptions associated with the idea of discreteness are robust.

We claim that the development of the concept of density is a case of conceptual change in mathematics learning. According to the conceptual change theoretical framework developed by Vosniadou (1994b, 2002),

- we assume that the idea of discreteness is a fundamental presupposition which constrains students' understanding of the structure of the set of rational numbers. Therefore, we expect students to generate errors that reflect the presupposition of discreteness.

- we assume that the understanding of density is a slow and gradual process, and not an "all or nothing" situation. Therefore, we expect to diagnose intermediate levels of understanding, reflecting students' efforts to assimilate new information about rational numbers in their pre-existing structures of knowledge about natural numbers. We expect that students who belong to intermediate levels of understanding have misconceptions that can be explained as synthetic models (Vosniadou, 1994b).

To make the point that understanding about rational numbers is not indiscriminately difficult we also investigate students' understanding about the algebraic properties of rational numbers ("every number $\neq 0$ has an inverse and an opposite number"). Contrary to the case of the structure of rational numbers, which is radically different from that of natural numbers, natural and other rational numbers share the same algebraic properties. Consequently, in this case, knowledge about natural numbers supports new understandings. On this basis, we assume that students perform adequately in new problems pertaining to the algebraic properties mentioned above. 


\section{Method}

\subsection{Participants}

The participants of the study were 16 ninth graders (approximately 15 years of age), from the same class in a middle class school in the Athens area. Participation in the study was voluntary and, according to their teacher, participants represented various levels of performance in mathematics.

By the time we interviewed them, our participants had finished a review of everything they were supposed to know about real numbers, including operations, turning a fraction into a decimal and vice versa, comparing and ordering numbers. They had also used the number line extensively, as a way to represent real numbers. Learning about density is not an explicit goal of the procedure-oriented Greek curriculum. Still, in their books there appear many tasks that relate to the concept of density. For example, seventh graders are explicitly taught how to find a fraction between two pseudo-successive fractions like $3 / 5$ and $4 / 5$. Eighth graders are explicitly taught how to approximate $\sqrt{2}$ with two rational numbers. Our ninth grade participants, in the first chapter of their mathematics book, had to solve exercises like the following: "Given that $3.14<$ pi $<3.15$, between which numbers is the area of the circle with radius $r=10 \mathrm{~cm}$ ?". Their mathematics teacher, who was teaching these students since grade 7 , informed us that the fact that there are infinitely many numbers in an interval had been mentioned in the classroom. Although he predicted that the tasks might be difficult for the students, he explained this difficulty by saying that this was eighth grade material and that it was possible that students would not remember it.

\subsection{Procedure}

All students were individually interviewed. The interview took place at their school, during regular school hours. Each interview lasted about one hour and covered many aspects of the number concept. In this article, we will only refer to the results pertaining to the properties of the set of rational numbers described above. All interviews were recorded and transcribed for the purposes of the present study. During the interview, each student was presented with a paper-and-pencil questionnaire that will be described in the next session. Students were asked to think aloud and to comment on their own answers.

\subsection{Materials}

The questionnaire, which is presented in Table 1, was empirically tested in a pilot study, for which a larger set of questions was originally developed. The present questions were selected from the original pool and were elaborated on the basis of the pilot study. The questionnaire includes the questions $A_{1}, A_{2}$ pertaining to the algebraic properties of real number; $\mathrm{D}_{\mathrm{a} 1}, \mathrm{D}_{\mathrm{a} 2}, \mathrm{D}_{\mathrm{a} 3}, \mathrm{D}_{\mathrm{b} 1}, \mathrm{D}_{\mathrm{b} 2}$, pertaining to density; $\mathrm{P}_{1}, \mathrm{P}_{2}, \mathrm{P}_{3}, \mathrm{P}_{4}$ were asked for the purpose of clarification. 
Table 1

Questions used during the interview

\begin{tabular}{|c|c|}
\hline & Preliminary questions \\
\hline $\mathrm{P}_{1}$ & $\begin{array}{l}\text { Suppose that a friend of yours does not know what the set of real numbers is. What } \\
\text { would you say to make him/her understand? }\end{array}$ \\
\hline \multirow[t]{2}{*}{$\mathrm{P}_{2}$} & Which of the following numbers are real numbers? Choose with a $\checkmark$. \\
\hline & $\begin{array}{llllll}5 & 3.21 & \sqrt{2} & -1 / 2 & 0.9999999 \ldots & 1 /(\sqrt{2}+1)\end{array}$ \\
\hline $\mathrm{P}_{3}$ & Which is the opposite of 2 ? \\
\hline \multirow[t]{2}{*}{$\mathrm{P}_{4}$} & Which is the inverse of $2 ?$ \\
\hline & Questions about algebraic properties \\
\hline \multirow[t]{3}{*}{$\mathrm{A}_{1}$} & Is there an opposite number for $\sqrt{3}$ ? \\
\hline & (i) Yes, there is and it is...... \\
\hline & (ii) No, there is not, because...... \\
\hline \multirow[t]{4}{*}{$\mathrm{A}_{2}$} & Is there an inverse number for $0.02506 ?$ \\
\hline & (i) Yes, there is and it is...... \\
\hline & (ii) No, there is not, because...... \\
\hline & Questions about density \\
\hline \multirow[t]{3}{*}{$\mathrm{D}_{\mathrm{a} 1}$} & Between the number 0.001 and the number 0.01 \\
\hline & (i) There is only one number and that number is...... \\
\hline & (ii) There is no other number(iii) (Else)...... \\
\hline \multirow[t]{3}{*}{$\mathrm{D}_{\mathrm{a} 2}$} & Between the number $3 / 8$ and the number $5 / 8$ \\
\hline & (i) There is only one number and that number is...... \\
\hline & (ii) There is no other number(iii) (Else)...... \\
\hline $\mathrm{D}_{\mathrm{a} 3}$ & How many numbers are there between 0.005 and $0.006 ?$ \\
\hline $\mathrm{D}_{\mathrm{b} 1}$ & How many numbers are there between $5 / 8$ and $8.5 ?$ \\
\hline $\mathrm{D}_{\mathrm{b} 2}$ & How many numbers are there between $2 / 5$ and $4 / 7 ?$ \\
\hline
\end{tabular}

At the beginning of the interview, it was made explicit to students that, unless stated otherwise, the term "number" refers to elements of the set of real numbers. ${ }^{1}$ We used the questions $\mathrm{P}_{1}, \mathrm{P}_{2}$ to avoid misunderstandings because of the wrong use of terms. Unless mentioned by the student herself, we made clear that "every number you know belongs to the set of real numbers". By the end of the discussion, it was made clear that any number, regardless of the way it is represented, is an element of the set of real numbers.

We used the questions $\mathrm{P}_{3}, \mathrm{P}_{4}$ to make sure that the students knew what the terms "opposite" and "inverse" number mean. All students were familiar with these terms. However, in some cases, students mixed up the terms, saying for example that the inverse number of 2 is -2 . In those cases, we reminded the student of the correct use of terms.

During the interview, all participants were presented with questions $\mathrm{D}_{\mathrm{a} 1}, \mathrm{D}_{\mathrm{a} 2}$, $\mathrm{D}_{\mathrm{a} 3}$. Students who answered that there are infinitely many numbers between the

\footnotetext{
${ }^{1}$ The term "real numbers" was deliberately used in all questions. Ninth graders always refer to the broader set of real numbers. The term "set of rational numbers" would only confuse them.
} 
two given numbers in all three questions, answered in addition $\mathrm{D}_{\mathrm{b} 1}$ and $\mathrm{D}_{\mathrm{b} 2}$, in which they had to specify how many numbers exist between a decimal and a fraction and between two dissimilar fractions. The interviewer explicitly informed the students that the numbers involved in each case are not equal. The purpose of $D_{b 1}$ and $\mathrm{D}_{\mathrm{b} 2}$ was to test whether a student has achieved what we consider in this case to be deep understanding of the structure of the set of rational numbers, that is to be able to answer that between any two different rational numbers, no matter of the way they are represented, there are infinitely many numbers. If this is the case, we expect the student to be able to answer $\mathrm{D}_{\mathrm{b} 1}$ and $\mathrm{D}_{\mathrm{b} 2}$ without turning the fraction into a decimal (or vice versa), or make the two fractions similar.

\section{Results}

Students' responses to questions $\mathrm{A}_{1}, \mathrm{~A}_{2}$ and $\mathrm{D}_{\mathrm{a} 1}, \mathrm{D}_{\mathrm{a} 2}, \mathrm{D}_{\mathrm{a} 3}$, along with the corresponding frequencies are presented in Table 2.

\subsection{Algebraic properties}

As far as questions $A_{1}$ and $A_{2}$ are concerned, we did not evaluate whether our participants were able to state correctly the specific opposite and inverse numbers. Instead, we were interested to see whether they would be able to assign to the given numbers the algebraic properties that they usually assign to natural numbers. Although they were not familiar with the form of the numbers asked, all students answered that the opposite and inverse numbers exist. In particular, they showed a strong tendency to begin with the presupposition that these numbers do exist, and then try to find them.

They typically used expressions such as the following:

"I believe it exists. Now, I don't know if I can write it down correctly."

"The opposite? There must be an opposite... It is the square root of minus three, I think!"

We detected this tendency even more clearly in the case of $A_{2}$. Students typically started with the presupposition that the particular inverse number exists:

"There is, I know there is. But, I personally don't know which number it is." "There is an inverse. (...) First we have to turn this number into a fraction... Yes... There is no doubt there is... I don't remember how to turn a decimal into a fraction, though."

Both students who answered that there is no inverse for 0.02506 followed a different line of reasoning: they tried to find the number, before deciding whether it exists. This is reflected in their answers.

"The inverse of this number... Now, can this thing I'm thinking of possibly exist? (...) I don't think there is. (...) It is rather strange to have a decimal denominator (...) I haven't seen such thing before, I guess it's not allowed." 
Table 2

Categories of students' responses to each question and corresponding frequencies ${ }^{\mathrm{a}}$

\begin{tabular}{llr}
\hline $\begin{array}{l}\text { Questions about algebraic } \\
\text { properties }\end{array}$ & $\begin{array}{l}\text { Categories of responses to the } \\
\text { questions about algebraic } \\
\text { properties }\end{array}$ & $\begin{array}{l}\text { Frequency of students' } \\
\text { responses }\end{array}$ \\
\hline $\mathrm{A}_{1}$ & The opposite exists & 16 \\
& The opposite does not exist & 0 \\
$\mathrm{~A}_{2}$ & The inverse exists & 14 \\
& The inverse does not exist & 2 \\
\hline
\end{tabular}

\begin{tabular}{|c|c|c|}
\hline Questions about density (A) & $\begin{array}{l}\text { Categories of responses to the questions } \\
\text { about density (A) }\end{array}$ & $\begin{array}{l}\text { Frequency of students' } \\
\text { responses }\end{array}$ \\
\hline $\mathrm{D}_{\mathrm{a} 1}$ & ...there is no other number & 3 \\
\hline \multirow[t]{2}{*}{ Between 0.001 and $0.01 \ldots$} & $\begin{array}{l}\text {...there is finite number of numbers } \\
\text { (more than } 0 \text { ) }\end{array}$ & 10 \\
\hline & $\begin{array}{l}\text {...there are infinitely many } \\
\text { numbers }\end{array}$ & 3 \\
\hline $\mathrm{D}_{\mathrm{a} 2}$ & ...there is only one number & 9 \\
\hline \multirow[t]{3}{*}{ Between $3 / 8$ and $5 / 8 \ldots$} & $\begin{array}{l}\text {...there are "infinitely many", } \\
\text { numbers, all equal to } 4 / 8\end{array}$ & 2 \\
\hline & $\begin{array}{l}\text {..there is finite number of numbers } \\
\text { (more than } 1 \text { ) }\end{array}$ & 3 \\
\hline & $\begin{array}{l}\text {...there are infinitely many } \\
\text { numbers }\end{array}$ & 2 \\
\hline $\mathrm{D}_{\mathrm{a} 3}$ & ...there is no other numbers & 9 \\
\hline \multirow[t]{2}{*}{ Between 0.005 and $0.006 \ldots$} & ...there is finite number of numbers & 4 \\
\hline & $\begin{array}{l}\text {...there are infinitely many } \\
\text { numbers }\end{array}$ & 3 \\
\hline
\end{tabular}

Questions about density (B) Categories of responses to the questions about density (B)

\begin{tabular}{lll}
\hline $\mathrm{D}_{\mathrm{b} 1}$ & Before I answer "infinitely many", \\
Between 5/6 and 8.5 & I have to turn the decimal into a \\
& fraction (or vice versa) \\
& I can answer "infinitely many", \\
& without turning the decimal into \\
& a fraction (or vice versa) \\
& Before I answer "infinitely many", \\
& I have to make the fractions \\
& similar \\
$\mathrm{D}_{\mathrm{b} 2}$ & I can answer "infinitely many", \\
Between $2 / 5$ and $4 / 7$ & without making the fractions \\
& similar
\end{tabular}

\footnotetext{
${ }^{\mathrm{a}}$ For each one of the questions $\mathrm{A}_{1}, \mathrm{~A}_{2}, \mathrm{D}_{\mathrm{a} 1}, \mathrm{D}_{\mathrm{a} 2}, \mathrm{D}_{\mathrm{a} 3}$, the total of student responses is 16 . According to our design, a student was asked question $\mathrm{D}_{\mathrm{b} 1}$, only in case he/she answered "infinitely many" to all three questions $\mathrm{D}_{\mathrm{a} 1}, \mathrm{D}_{\mathrm{a} 2}, \mathrm{D}_{\mathrm{a} 3}$. Question $\mathrm{D}_{\mathrm{d} 2}$ was asked, only in case the student was able to answer $\mathrm{D}_{\mathrm{b} 1}$, without turning the decimal into a fraction, or vice versa. Only one of our participants made it to question $\mathrm{D}_{\mathrm{b} 1}$. This student explicitly said that he had to turn $5 / 6$ into a fraction, so question $\mathrm{D}_{\mathrm{b} 2}$ was never asked.
} 


\subsection{Structural properties}

In a study of 16 participants, quantitative results are not of much importance. Still, in this case, the results displayed on Table 2 give an adequate first impression of students' performance regarding questions $\mathrm{D}_{\mathrm{a} 1}, \mathrm{D}_{\mathrm{a} 2}, \mathrm{D}_{\mathrm{a} 3}$. The most frequent answer given by our participants is that there is a finite number of numbers, either 0 or $\neq 0$, between the given numbers. We should point out that two of our participants answered that there are infinitely many numbers between $3 / 8$ and $5 / 8$, but when asked to describe some of these numbers, they came up with different representations of $4 / 8$ such as $4.0 / 8, \sqrt{16} / 8$ and $32 / 64$. We did not categorize this answer as a typical "finite number of numbers" answer (see Table 2). We will refer to these students as $S_{1}$ and $S_{2}$. None of our participants has showed what we consider, in this case, to be deep understanding of the structure of the set of rational numbers. Students' responses were grouped in five different categories, varying from a naive account of the structure of rational numbers to gradually more sophisticated accounts.

\subsubsection{Naive discreteness}

Students who consistently answered that between two pseudo-successive rational numbers, there is no other number were placed in this category. Consistency in this case reflects the fact that the students responded similarly, both in the case of decimals and in the case of fractions. Students in this category also stated that there is a finite number of numbers between the decimals with different number of decimal digits. Data provided in the following example come from one student. The same holds for each one of the examples presented in this section.

Example 1: "There is no other number [between $0.005 \& 0.006$ ], because after 0.005 comes 0.006 "'[Between 3/8 and 5/8,] It's just one, 4/8. And for that, I'm sure". "0.01 is the same as 0.010 . So, starting from 0.001 , there are the numbers 0.002 , up to 0.009 '.

\subsubsection{Advanced discreteness}

Students who consistently answered that there is a finite number $(\neq 0)$ of numbers between two pseudo-successive rational numbers were placed in this category. Consistency in this case also reflects the fact that the students responded similarly, both in the case of decimals and in the case of fractions. Students in this category also stated that there is a finite number of numbers between the decimals with different number of decimal digits. Student $S_{1}$ was also placed in this category.

Example 2: "Between these two [0.005 \& 0.006] you can find (he writes:) 0.0051, $0.0052, \ldots, 0.0059$ ". "[Between $3 / 8$ and 5/8] there are as many numbers, as it takes to cover the space between 3 and 5: These are 3.1, 3.2, 3.3 and so on..." 


\subsubsection{Discreteness-density}

Students who answered that between two rational numbers, there are infinitely many numbers in some, but not in all cases, were placed in this category. Student $\mathrm{S}_{2}$ was also placed in this category.

Example 3: "Between these two $[0.001 \& 0.01]$ there are the numbers which are greater than 0.001 and smaller than 0.01 . (...) So, there are 99 numbers in between... Wait a minute! There are 9, because these two differ for one decimal digit." "[Between 3/8 and 5/8] There are infinitely many numbers"

And he explained:

"Between these two (0.005 \& 0.006), you can find 9 numbers, when they are in decimal form. But, if you turn them into fractions, you can find more: You can find infinitely many numbers in between".

Example 4: " 0.01 is the same as 0.010 . So starting from 0.001 , there are 0.002 , 0.003 , and so on, up to 0.009 '.

"Between 0.005 and 0.006 , there are many-many numbers: There can be 0.0051 , 0.0052 and so on. But there can also be 0.00511 or 0.005831 or even more".

When we asked him to further elaborate his opinion, he explained:

"These two $(0.005 \& 0.006)$ are both ...how can I put it. . there are in the same group. So, you can add after 5 as many digits as you like before it reaches 0.006 . But, between 0.001 and 0.01 , you can only put these numbers $(0.002$, $0.003 . . ., 0.009)$ ".

\subsubsection{Naive density}

Only one student was placed in this category. This student answered that there are infinitely many numbers, both in the case of decimals and in the case of fractions. However, he was not able to answer immediately that there are infinitely many numbers between a decimal and a fraction, although he was informed that these numbers are not equal. Instead, he explicitly said that he needed to turn the fraction into a decimal first. He did not give an adequate explanation about it. ("I don't know... I guess it's easier that way...")

\subsubsection{Sophisticated density}

This category corresponds to a rather sophisticated understanding of density. To be placed in this category, a student must answer consistently that between any two non-equal rational numbers there are infinitely many rational numbers, regardless of the way they are represented. None of our participants belonged in this category.

The five categories and their relation to the questions about density are summarized in Table 3. 
Table 3

Categories of students' responses to all questions about density

\begin{tabular}{|c|c|c|c|c|c|}
\hline $\begin{array}{l}\text { Categories of } \\
\text { responses }\end{array}$ & $\mathrm{D}_{\mathrm{a} 3}$ & $\mathrm{D}_{\mathrm{a} 2}$ & $\mathrm{D}_{\mathrm{a} 1}$ & $\mathrm{D}_{\mathrm{b} 1}$ & $\mathrm{D}_{\mathrm{b} 2}$ \\
\hline $\begin{array}{l}\text { Naive discrete- } \\
\text { ness }(9 / 16)\end{array}$ & No other & Only one & $\begin{array}{l}\text { Finite number } \\
\text { of numbers } \geq 0\end{array}$ & - & - \\
\hline $\begin{array}{l}\text { Advanced dis- } \\
\text { creteness }(2 / 16)\end{array}$ & $\begin{array}{l}\text { Finite number } \\
\text { of numbers }>0\end{array}$ & $\begin{array}{l}\text { Finite number } \\
\text { of numbers }>1\end{array}$ & $\begin{array}{l}\text { Finite number } \\
\text { of numbers } \geq 0\end{array}$ & - & - \\
\hline $\begin{array}{l}\text { Discreteness- } \\
\text { density }(4 / 16)\end{array}$ & \multicolumn{5}{|c|}{ The "infinitely many" answer appears in some, but not in all cases } \\
\hline $\begin{array}{l}\text { Naive density } \\
(1 / 16)\end{array}$ & Infinitely many & Infinitely many & Infinitely many & $\begin{array}{l}\text { Need to turn the } \\
\text { one into the } \\
\text { other's form }\end{array}$ & $\begin{array}{l}\text { Need to make } \\
\text { them similar }\end{array}$ \\
\hline $\begin{array}{l}\text { Sophisticated } \\
\text { density }(0 / 16)\end{array}$ & Infinitely many & Infinitely many & Infinitely many & $\begin{array}{l}\text { No need to turn } \\
\text { the one into the } \\
\text { other's form }\end{array}$ & $\begin{array}{l}\text { No need to } \\
\text { make them } \\
\text { similar }\end{array}$ \\
\hline
\end{tabular}

\section{Discussion}

The results of the present study confirmed our hypothesis that the students would find the questions about the algebraic properties of real numbers easy to answer. Despite our efforts to make things difficult for them, our participants did not hesitate to say that the opposite and inverse number of the given numbers did exist, regardless the possibility of finding them. A probable explanation for this certainty is that it derives from their knowledge about natural numbers: knowing that natural numbers do have an inverse and an opposite number, a fact that was also reminded to them through the preliminary questions $\mathrm{P}_{3}, \mathrm{P}_{4}$, students were ready to accept that these properties can be assigned to rational and irrational numbers, as well.

The results also confirmed our prediction that deciding about the number of numbers between two given rational numbers would be a rather demanding task. As expected, the development of the concept of density was found to be a gradual process. Five categories of responses were identified, corresponding to different levels of understanding of the structure of rational numbers, varying from the most naive to what we defined as sophisticated. The presupposition of discreteness clearly shapes students' responses in the first two categories. Students in these categories generate responses which are limited to subsets of rational numbers that preserve the property of discreteness (for example, $0.001,0.002,0.003 \ldots$, or $3 / 8,4 / 8$, $5 / 8, \ldots$ or $3.1 / 8,3.2 / 8,3.3 / 8 \ldots$ or $0.0051,0.0052, \ldots$ etc.). By adding a decimal digit to the given numbers, students in the second category have actually made the first step towards conceiving the infinite number of numbers in the interval. Yet, the next step of adding another decimal digit should not be taken for granted. Students in the discreteness-density category give seemingly inconsistent answers, in the sense that they do not answer in the same way questions concerning decimals with the same number of decimal digits, decimals with different number of decimal 
digits and fractions. Still, students in this category explicitly described how they made sense of this inconsistency, referring to different groups of numbers. Although further investigation is needed, we believe that these students have developed some knowledge as far as particular aspects of rational numbers are concerned. Yet, this knowledge is not necessarily transferred to all rational numbers. For instance, the student mentioned in example 1, a very competent student in mathematics, insisted that there are infinitely many numbers between two fractions, even in the case of dissimilar fractions. And, although he was clearly able to turn a decimal into a fraction, he insisted that between two decimals there is a finite number of numbers. Only after the interview, when he was explicitly informed about this inconsistency, did he realize that he had used different ways to think about fractions and decimal numbers. The presupposition of discreteness is still reflected in some aspects of the discreteness-density students' responses. The student who was placed in the naive density category was no longer constrained by the presupposition of discreteness. Yet, he was able to talk about density only by referring to sets of numbers of the same representation (either decimals, or fractions).

The results support our hypothesis that the understanding of density is a slow, gradual process which is constrained by the presupposition of discreteness. As students enrich their knowledge and acquire expertise in handling rational numbers, they generate gradually more sophisticated accounts of the structure of the set of rational numbers. Students of the second and third category have misconceptions that can be explained as synthetic models (Vosniadou, 1994b) reflecting the assimilation of new information into prior knowledge structures. For example, student $\mathrm{S}_{2}$, who consistently answered that there are infinitely many numbers between decimals, gave a completely different response in the case of fractions, referring to the infinite representation of one single fraction. The results suggest that the understanding of density requires reorganization of prior knowledge about natural numbers. So, it is a case of conceptual change in mathematics learning.

In this article, we argued that cases where understanding requires conceptual change can and, in fact, do occur in mathematics learning. This may suggest that mathematics education can profit from the educational guidelines provided by the conceptual change approach literature (Vosniadou, 2002). Increasing mathematics educators' sensitivity about conceptual change problems is a first step and may help them to explain why students keep "forgetting" some things, as in the case of our participants' mathematics teacher. It may also answer some of the questions about communicational problems in the classrooms (Sfard, 1994): what seems to be "inconsistent" to the one who thinks in terms of rational numbers, might not strike as odd to the one who thinks in terms of fractions and decimals. One has to bear in mind that presuppositions which constrain learning are not under the conscious control of the learner (Vosniadou, 2002). It is important to create learning environments that allow students to express and elaborate their opinions, so that they become aware of their beliefs. Finally, when learning requires reorganization of prior knowledge structures, immediate results should not be expected, even after carefully designed instruction. Conceptual change may prove to be a slow, time 
consuming process. However, the results in terms of understanding make the effort worthwhile.

\section{References}

Butterworth, B. (1999). The mathematical brain. London: Macmillan.

Carey, S. (1985). Conceptual change in childhood. Cambridge, MA: MIT Press.

Carey, S., \& Spelke, E. (1994). Domain specificity and conceptual change. In L. A. Hirschfeld, \& S. A. Gelman (Eds.), Mapping the mind: Domain specificity in cognition and culture (pp. 169-200). New York: Cambridge University Press.

Carey, S., \& Spelke, E. (1996). Science and core knowledge. Philosophy of Science, 63, 515-533.

Carpenter, T. P., Fennema, E., \& Romberg, T. A. (Eds.) (1993), Rational numbers: An integration of research. Hillsdale, NJ: Erlbaum.

Corry, L. (1993). Kuhnian issues, scientific revolutions and the history of mathematics. Studies in History and Philosophy of Science, 24, 95-117.

Crowe, M. (1975). Ten "laws" concerning patterns of change in the history of mathematics. Historia Mathematica, 2, 161-166 (Reprinted in Gilies, D. (Ed.). (1992). Revolutions in mathematics (pp. 15-20). Oxford: Oxford University Press.).

Crowe, M. (1992). Afterword: a revolution in historiography of mathematics?. In D. Gilies (Ed.), Revolutions in mathematics (pp. 306-316). Oxford: Oxford University Press.

Dauben, J. (1984). Conceptual revolutions and the history of mathematics: two studies in the growth of knowledge. In E. Mendelsohn (Ed.), Transformation and tradition in the sciences, essays in honour of I. Bernard Cohen (pp. 81-103). Cambridge University Press. (Reprinted in Gilies, D. (Ed.). (1992). Revolutions in mathematics (pp.15-20). Oxford: Oxford University Press.).

Dehaene, S. (1998). The number sense: How the mind creates mathematics. Harmondsworth, Middlesex, England: The Penguin Press (First published by Oxford University Press, 1997).

Fischbein, E. (1987). Intuition in science and mathematics. Dordrecht: Kluwer Academic Press.

Fischbein, E., Deri, M., Nello, M., \& Marino, M. (1985). The role of implicit models in solving problems in multiplication and division. Journal of Research in Mathematics Education, 16, 3-17.

Galistel, C. R., \& Gelman, R. (1992). Preverbal and verbal counting and computation. Cognition, 44, 43-74.

Gelman, R. (2000). The epigenesis of mathematical thinking. Journal of Applied Developmental Psychology, 21, 27-37.

Hannula, M., Maijala, H., Pehkonen, E., \& Soro, R. (2001). Taking a step to infinity: students' confidence with infinity tasks in school mathematics. Paper presented at the third European symposium on conceptual change, Turku, Finland.

Hartnett, P. M., \& Gelman, R. (1998). Early understandings of number: paths or barriers to the construction of new understandings?. Learning and Instruction, 8, 341-374.

Kitcher, P. (1992). The nature of mathematical knowledge. Oxford: Oxford University Press.

Kuhn, T. (1970). The structure of scientific revolutions. (2nd ed.). Chicago: Chicago Press (First edition: 1962).

Lakoff, G., \& Nunez, R. (2000). Where mathematics comes from: How the embodied mind brings mathematics into being. New York: Basic Books.

Limon, M. (2002). Conceptual change in history. In M. Limon, \& L. Mason (Eds.), Reconsidering conceptual change: Issues in theory and practice (pp. 259-289). Dordrecht: Kluwer Academic Publishers.

Lipton, J. S., \& Spelke, E. S. (2003). Origins of number sense: large numbers discrimination in human infants. Psychological Science, 4, 396-401.

Malara, N. (2001). From fractions to rational numbers in their structure: outlines for an innovative didactical strategy and the question of density. Proceedings of the European research in mathematics education II, February 24-27, Czech Republic.

Mason, L. (Ed.). (2001). Instructional practices for conceptual change in science domains [Special Issue]. Learning and Instruction, 11 (4/5). 
Merenluoto, K., \& Lehtinen, E. (2002). Conceptual change in mathematics: understanding the real numbers. In M. Limon, \& L. Mason (Eds.), Reconsidering conceptual change: Issues in theory and practice (pp. 233-258). Dordrecht: Kluwer Academic Publishers.

Merenluoto, K., \& Lehtinen, E. (this issue). Number concept and conceptual change: Outlines for new teaching strategies.

Moskal, B. M., \& Magone, M. E. (2000). Making sense of what students know: examining the referents, relationships and modes students displayed in response to a decimal task. Educational Studies in Mathematics, 43, 313-335.

Posner, G. J., Strike, K. A., Hewson, P. W., \& Gertzog, W. A. (1982). Accommodation of a scientific conception: towards a theory of conceptual change. Science Education, 66, 211-227.

Resnick, L. B., Nesher, P., Leonard, F., Magone, M., Omanson, S., \& Peled, I. (1989). Conceptual bases of arithmetic errors: the case of decimal fractions. Journal for Research in Mathematics Education, 20, 8-27.

Sfard, A. (1991). On the dual nature of mathematical conceptions: reflections on processes and objects as different sides of the same coin. Educational Studies in Mathematics, 22, 1-36.

Sfard, A. (1994). Mathematical practices, anomalies and classroom communication problems. In P. Ernest (Ed.), Constructing mathematical knowledge: Epistemology and mathematics education, studies in mathematics education (pp. 4). London: Falmer Press.

Stafylidou, S., \& Vosniadou, S. (this issue). Students' understanding of the numerical value of fractions: A conceptual change approach.

Stern, E. (2003). Knowledge restructuring as a powerful mechanism of cognitive development: how to lay an early foundation for conceptual understanding in science and mathematics. EARLI 10th biennal conference, Padova, Italy, August 26-30 (Keynote address).

Tall, D. (2001). Natural and formal infinities. Educational Studies in Mathematics, 48, 199-238.

Tirosh, D. (1991). The role of students' intuition of infinity in teaching the cantorian theory. In D. Tall (Ed.), Advanced mathematical thinking (pp. 133-166). Dordrecht: Kluwer Academic Publishers.

Vosniadou, S. (Ed.). (1994a). Introduction [Special issue]. Learning and Instruction, 4, 3-6.

Vosniadou, S. (1994b). Capturing and modelling the process of conceptual change [Special issue]. Learning and Instruction, 4, 45-69.

Vosniadou, S. (1999). Conceptual change research: State of the art and future directions. In W. Schnotz, S. Vosniadou, \& M. Carretero (Eds.), New perspectives on conceptual change (pp. 3-13). Oxford: Elsevier Science.

Vosniadou, S. (2002). Exploring the relationships between conceptual change and intentional learning. In G. M. Sinatra, \& P. R. Pintrich (Eds.), Prospects and problems for modes of intentional conceptual change (pp. 377-406). Mahwah, NJ: Lawrence Erlbaum Associates. 